\title{
Frontières
}

\section{La mort... y penser ensemble}

\section{Diane Laflamme}

Volume 19, numéro 2, printemps 2007

\section{Penser sa mort?}

URI : https://id.erudit.org/iderudit/017488ar

DOI : https://doi.org/10.7202/017488ar

Aller au sommaire du numéro

Éditeur(s)

Université du Québec à Montréal

ISSN

1180-3479 (imprimé)

1916-0976 (numérique)

Découvrir la revue

Citer ce document

Laflamme, D. (2007). La mort... y penser ensemble. Frontières, 19(2), 3-4. https://doi.org/10.7202/017488ar

Ce document est protégé par la loi sur le droit d'auteur. L'utilisation des services d'Érudit (y compris la reproduction) est assujettie à sa politique d'utilisation que vous pouvez consulter en ligne.

https://apropos.erudit.org/fr/usagers/politique-dutilisation/
Cet article est diffusé et préservé par Érudit.

Érudit est un consortium interuniversitaire sans but lucratif composé de l’Université de Montréal, l'Université Laval et l'Université du Québec à Montréal. Il a pour mission la promotion et la valorisation de la recherche. https://www.erudit.org/fr/ 


\section{LA MORT...

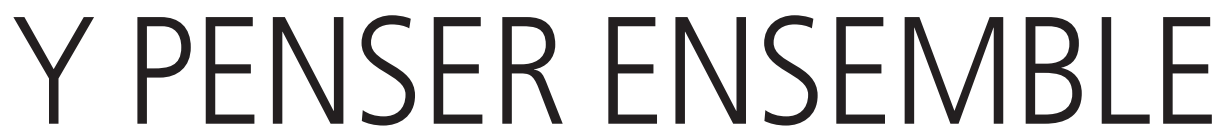

Diane Laflamme, Ph. D.

rédactrice en chef.

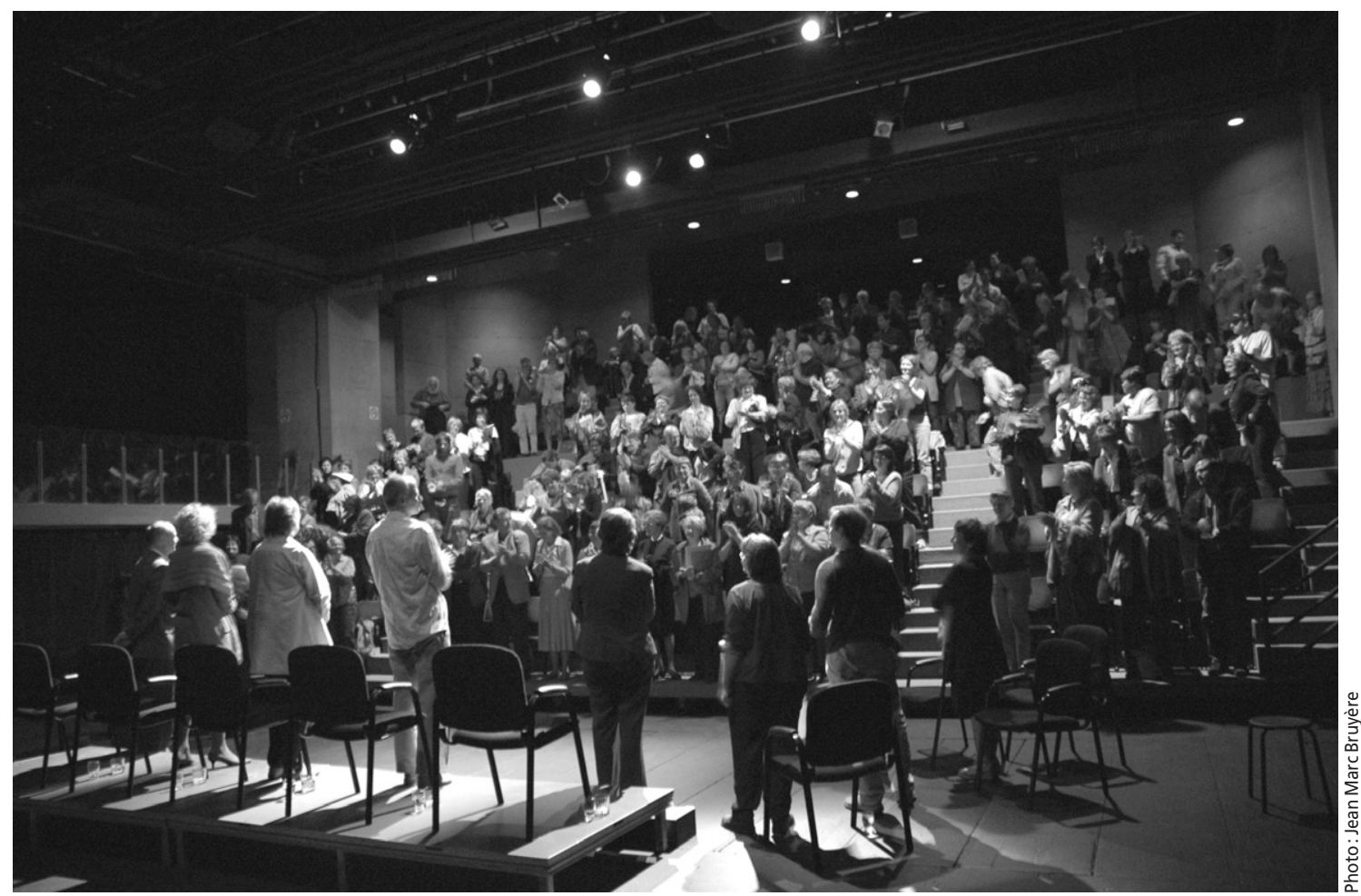

Clôture du spectacle littéraire "Et ils t'aideront à traverser... » conçu par Marie-Louise Leblanc et présenté à I'UQAM le lundi 7 mai 2007.

Bien sûr, il s'agit là d'une façon de parler. Même quand je vous dis : «Pensons-y ensemble», je m'attends à continuer individuellement l'enchaînement de mes propres pensées, sans avoir le moindre accès aux vôtres tant que vous ne prendrez pas la parole pour me dire ce que vous pensez. Lorsque nous pensons, nous sommes seuls avec nous-mêmes, même si nous nous intéressons à un objet choisi d'un commun accord. Penser n'est pas un processus collectif. Personne ne peut faire à ma place le travail qui fait émerger une pensée en moi. Nous pouvons «partager» nos pensées avec d'autres à travers des mots, parler de ce qui occupe nos pensées, mais le travail même qui consiste à penser - ou à arrêter de penser - nous sommes seuls pour l'accomplir' ${ }^{1}$.

Penser à la mort? Y penser ensemble? Oui, il le faut bien parfois. Cela nous amène à en parler entre nous ou encore à écouter quelqu'un dire comment il ou elle vit la confrontation à la mort. C'est ce que les quelque cent cinquante personnes qui ont répondu à l'invitation de Frontières ont eu l'occasion de faire le 7 mai dernier, au Studio-théâtre Alfred-Laliberté de l'Université du Québec à Montréal, alors que des acteurs professionnels ont prêté leur voix pour permettre à l'auditoire - qui les accompagnait «en pensée» - d'entendre ce qu'ont écrit des hommes et des femmes qui ont vu la mort faire irruption dans leur quotidien à la suite d'un accident, d'un diagnostic de maladie en phase terminale ou tout simplement à cause du grand âge ${ }^{2}$. Dans de tels moments où nous y pensons ensemble, même si c'est chacun dans son for intérieur, se révèle avec force la charge percutante de la prise de parole.

Penser la mort? Et même penser sa propre mort, comme le suggère le thème du présent numéro de Frontières? Oui, car la vie de la pensée nous rend capable de penser aussi ce qui nie la vie et la pensée. Penser la mort nous permettra de pouvoir parler d'un universel: l'être dans la mort. Penser la mort pourrait 
aussi nous aider à vivre notre humble petite histoire, dans sa singularité qui nous semble si loin de l'universel. Écoutons à ce sujet le témoignage de Bertrand Vergely. C'est le professeur de philosophie qui écrit et, en même temps, c'est le fils qui parle:

Maman est morte.

[...]

Durant les deux derniers mois de son existence lorsque les événements se précipitaient, il s'est agi de l'accompagner jusqu'aux extrémités de la vie [...] un côte à côte essentiel habité par le fait brut et nu, pour elle de mourir, et pour moi de la regarder mourir.

\section{$[\ldots]$}

Il faut dire nos combats concernant la vie et la mort. Il faut donner sa part à l'humain qui cherche à faire quelque chose de la mort, afin de fortifier les vivants demeurés sur la rive du temps face à l'océan sombre de l'au-delà. Mais il faut aussi parler de l'être dans la mort et dire les mystères et les surprises qu'il réserve, quand on le vit. Il y a là quelque chose qui aide à vivre. Quelque chose comme un grand souffle de force et de dignité dans un vertigineux tremblement de vie.

(Vergely, 2004, p. 7, 9)

Penser la mort peut aider à vivre. Pensons-y ensemble ${ }^{3}$ et puisse le vent de la pensée nous aider à faire corps non pas avec nos petites misères, mais avec ce grand souffle de force et de dignité dont nous parle Vergely et dont peuvent aussi témoigner celles et ceux qui choisissent la posture d'accompagnant au chevet de la personne qui meurt.

\section{Bibliographie}

VERGELY, B. (2004). Voyage au bout d'une vie, Paris, Bartillat.

\section{Notes}

1. Sur le travail de la pensée et le besoin de penser, voir Laflamme, dans ce numéro, p. 8-11.

2. Il s'agissait du spectacle littéraire intitulé «Et ils t'aideront à traverser...», organisé conjointement par les Productions «Et Jules à mes côtés... », par le Programme d'études sur la mort de l'UQAM et par la revue Frontières. Ce spectacle avait été conçu par Marie-Louise Leblanc, avec la participation de Stéphane Demers, Marie Eykel, Françoise Faucher, Jacques Lavallée et Josée Martin. La lecture des textes a été suivie d'une table ronde, portant sur l'accompagnement des personnes en fin de vie, animée par Ariane Émond et à laquelle participaient Manon Roy et François Forté de la Fondation Palli-Ami, le Dr Patrick Vinay de l'Unité de soins palliatifs de l'Hôpital NotreDame, Luce Des Aulniers et Johanne De Montigny qui enseignent au Programme d'études sur la mort, à l'UQAM.

3. Nous aurons l'occasion de penser ensemble à la mort autour des textes de la romancière et essayiste Christiane Singer le lundi 26 novembre 2007, alors que Frontières se joindra de nouveau à Marie-Louise Leblanc de Productions «Et Jules à mes côtés... » pour tenir à l'UQAM un spectacle littéraire au cours duquel la comédienne Françoise Faucher lira des extraits des Derniers fragments d'un long voyage (2007), Paris, Albin Michel.

\section{Revue FRONTIÈRES}

Programme d'études sur la mort UQAM

\section{Spectacle littéraire \\ Derniers fragments d'un long voyage de Christiane Singer}

Le $1^{\text {er }}$ septembre 2006, un jeune médecin à l'œil froid

annonce à Christiane Singer qu'elle a tout au plus six mois à vivre.

L'auteure va tenir un journal de bord. Pour témoigner et partager...

"Une maladie est en moi, mais mon travail va être de ne pas être moi dans la maladie.

Ce qu'il y a à vivre, il va falloir le vivre."

Christiane Singer

Derniers fragments

d'un long voyage

a Albin Michel

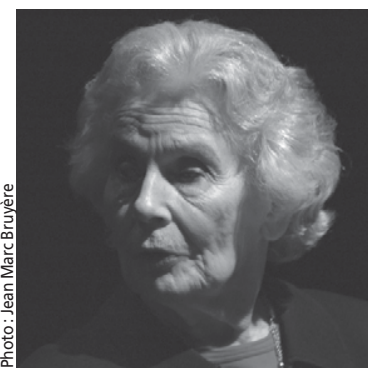

Montage/mise en lecture/choix musicaux: Marie-Louise Leblanc

Extraits de textes lus par Françoise Faucher

Le lundi 26 novembre 2007, à $20 \mathrm{~h}$, à la salle Marie-Gérin-Lajoie de I'UQAM 405, rue Sainte-Catherine Est, Pavillon Judith-Jasmin, Niveau Métro Berri-UQAM Billeterie UQAM : (514) 987-3456

Information: (514) 289-1709. 